p764 Pot of gold:

Marijuana researchers fight for their right to grow the plants.

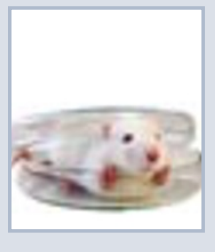

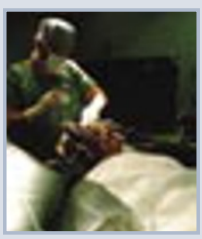

p770 Take two:

Controversial

Parkinson's disease

treatment is once again

in trials.

\title{
Pfizer lawsuit spotlights ethics of developing world clinical trials
}

On 4 June, the Nigerian government took an unprecedented step in public health, suing pharmaceutical giant Pfizer for $\$ 7$ billion in damages for an allegedly illegal drug trial the company had conducted 11 years earlier.

The case could drag on for years, but if Nigeria wins, pharmaceutical companies may shy away from conducting high-risk clinical trials in developing countries.

Over the past two decades, companies have increasingly run trials in countries with few public health resources. "Sometimes they go because that's where the disease is. Sometimes they go because it's cheaper and easier to get things approved," says Arthur Caplan, director of the University of Pennsylvania's Center for Bioethics.

International groups such as the Council for International Organizations of Medical Sciences and the World Medical Association have set guidelines intended to guarantee that participants of clinical trials, no matter where they live, are treated according to the same ethical standards. But it's up to individual countries to adopt and enforce those recommendations.

"Guidelines merely guide, they don't bind," says Jerome Singh, head of the Bioethics and Health Law Programme at the Center for the AIDS Programme of Research in South Africa.

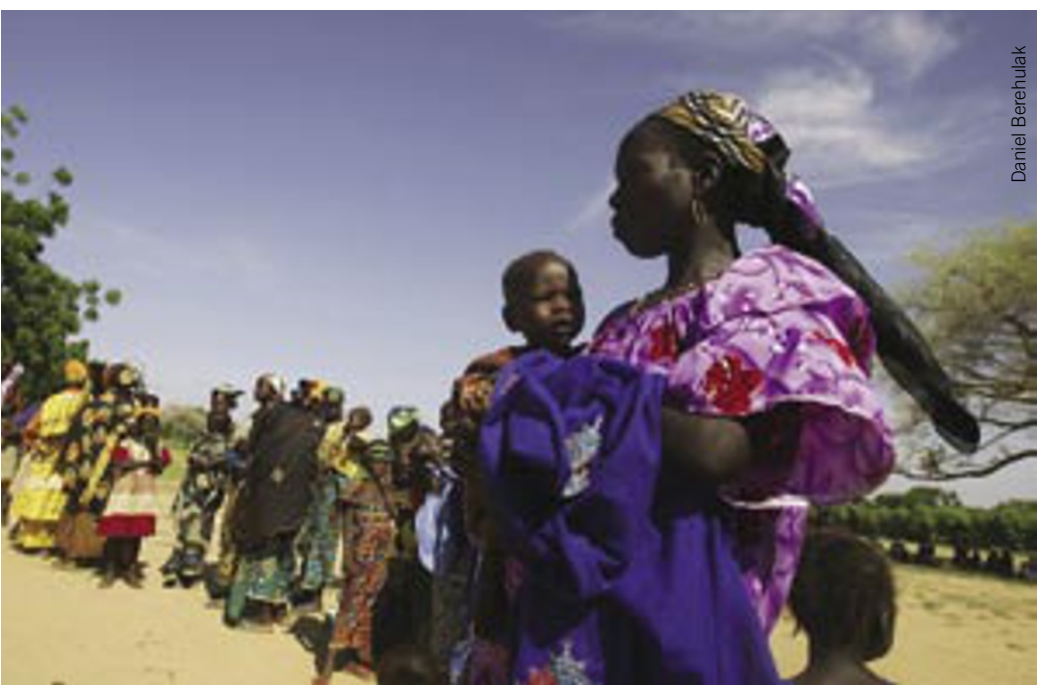

Trial and error: Lax oversight of trials in developing nations has led to serious violations.
Few developing countries have the resources needed to enforce the guidelines and make sure that research is conducted ethically. As a result, there are several examples of scientists, even those from prestigious institutions, who have been caught violating ethical rules.

In 2001, for example, Johns Hopkins University banned biologist Ru Chih C. Huang from conducting research on people, following reports that she had been testing an experimental cancer drug in India without the knowledge or consent of the university or the government.

The following year, an investigation by the US Office for Human Research Protections (OHRP) revealed that two Harvard University professors had been collecting blood from people in rural China to study common conditions such as asthma and high blood pressure without a proper ethics review.

"The problem is that in many places there is no regulatory framework to guide the studies," says Richard Chaisson, director of Johns Hopkins University's Center for Tuberculosis Research.

In most of the developed world ethics panels, known as institutional review boards (IRBs), are responsible for evaluating informed consent and other ethical issues in a research proposal. But some developing countries have few established IRBs to turn to. The OHRP directory lists just one for all of Rwanda, for example. Even countries that have more IRBs aren't assured a thorough review because the board's members may not be trained to spot red flags.

In some cases, the committees may even intentionally let things slide because they don't want to be seen as difficult. "In many developing countries, trials actually get facilitated rather than going through rigorous review because the institutions are afraid of losing research funding," says Singh.

Even trained ethicists disagree about the best way to conduct research in developing countries. The biggest source of contention is whether new therapies should be tested against the best existing treatment anywhere in the world or the best available where the trial is conducted.

The World Medical Association weighs in on the side of the best existing treatment. But there are good reasons not to offer the best treatment in places where it wouldn't otherwise be available, cautions Singh. "The standard of care that you introduce should not be an island that nobody else can access," he says, "because then the mere offering of that standard of care becomes an undue inducement to enroll in that study."

In Nigeria, the government charges that Pfizer had neither parental consent nor federal approval to give Trovan (trovafloxacin), an experimental antibiotic, to 100 children with meningococcal meningitis in Kano. The company is also being sued by the local government in Kano in a separate $\$ 2$ billion lawsuit, which alleges that the antibiotic caused deafness, paralysis, brain damage, blindness and even death in some of the children.

Pfizer denies any wrongdoing. "We continue to maintain - in the strongest terms - that the Nigerian government was fully informed in advance of the clinical study; that the study was conducted appropriately, ethically and with the best interests of patients in mind; and that it helped save lives," says Bryant Haskins, a spokesperson for Pfizer.

Trovan is not authorized for use on children in the US. The Food and Drug Administration approved the drug for adults in 1997, but reports of serious liver problems led the agency in 1999 to limit the drug's use to the treatment of lifethreatening infections.

Inconsistent oversight of research in developing countries means that drug companies are often left to police their own actions. Whether Pfizer is guilty or not remains to be seen, but if Nigeria wins, says Singh, "It might make pharmaceutical companies a bit more wary about doing whatever they want to do."

Cassandra Willyard, New York 